\title{
Study of Laryngo Tracheo Bronchial Foreign Bodies
}

\author{
T. Rajendra Prasad ${ }^{1}$, N. Subrahmanyam ${ }^{2}$, K. Santhaiah ${ }^{3}$ \\ ${ }^{1,2,3}$ Dept of Otorhinolaryngology, Guntur Medical College, Guntur, India,4.
}

\begin{abstract}
Foreign body aspiration is worldwide health problem which can result in life threatening complications especially in pediatric patients which demand immediate action and management has got lot of significance. As such accidents due to inhalation of foreign bodies continue to take formidable toll of lives every year. This study is about our experience with fifty foreign bodies in laryngotrachea bronchial tree. The occurrence of foreign bodies in air passages is an emergency problem both in adults \& children. They are mostly accidental, negligence; food habits, age and mental condition of the patient are the major contributory factors for the lodgment of foreign bodies in the air passages. Because of the danger of complications, like respiratory distress, they have to be attended as emergencies. Bronchoscopic removal of foreign body under direct visualization of the tract is the main stay of treatment.

Recent advances in radiology (Fluoroscopy, CT, and MRI) flexible bronchoscopy, plays a greater role as a sort of confirmation of diagnosis.
\end{abstract}

Keywords: FB - Foreign body, CT - Computed tomography, MRI - Magnetic resonance imaging, Exogenous Endogenous, Bronchus, Otolaryngologist.

\section{Introduction}

Foreign body (FB) is defined as endogenous or exogenous substance which is abnormally found in anatomical site. Foreign body aspiration is a worldwide health problem which can result in life threatening complications. They can occur among children less than five years of age, and sharp foreign bodies like bone pieces, metallic objects like pins and wires are also seen in children, adolescents and adults. Generally organic materials such as nuts and seeds, metallic objects like coins and battery cell are commonly aspirated. Imaging studies such as plain x-rays are very useful and are diagnostic for sharp foreign bodies as most of them are metallic and radio-opaque. Rigid bronchoscopy is the standard procedure for the removal of foreign bodies, but flexible bronchoscopy is used for the removal of foreign bodies which have entered into the peripheral bronchi. It is a challenging task to the otolaryngologist to diagnose and remove the foreign body in acute conditions by flexible bronchoscopy, rigid bronchoscopy, tracheotomy, tracheostomy and thoracotomy with bronchotomy.

The objective of this retrospective study is to assess the number of patients in three year period reporting to the causality and pediatric department, the type of presentation, the nature of FB and role of bronchoscopy in diagnostic and therapeutic intervention.

Materials And Methods: This is a retrospective study of 50 patients in a three year period from 2004 - 2007 reporting to the Causality, Pediatric and E.N.T departments at Government general hospital, Guntur, out of which male -30 and females -20 , (Table-1).

Table - 1. Gender distribution

\begin{tabular}{|l|c|c|}
\hline Sex & Number of patients & Percentage \\
\hline Male & 30 & $60 \%$ \\
\hline Female & 20 & $40 \%$ \\
\hline Total & 50 & $100 \%$ \\
\hline
\end{tabular}

Most commonly 6 months to 10 years age group children get affected. The youngest patient was six months old and the oldest one was 53 years old with broken tracheostomy tube. Details of age distribution are outlined in Table -2

Table - 2. Age distribution

\begin{tabular}{|c|c|c|}
\hline Age in years & Number of cases & Percentage \\
\hline $0-1$ & 8 & $16 \%$ \\
\hline $1-2$ & 4 & $8 \%$ \\
\hline $2-3$ & 14 & $28 \%$ \\
\hline $3-4$ & 17 & $34 \%$ \\
\hline$>4$ & 7 & $14 \%$ \\
\hline Total & 50 & $100 \%$ \\
\hline
\end{tabular}


All the patients were evaluated with a detailed history, clinical examination, chest x-ray, CT scan chest where ever required. Patients presenting sudden choking required immediate surgical intervention. Below are some of the x-ray films shown for clinical correlation

Figures -1 to 4, showing shifting foreign body (Head pin).

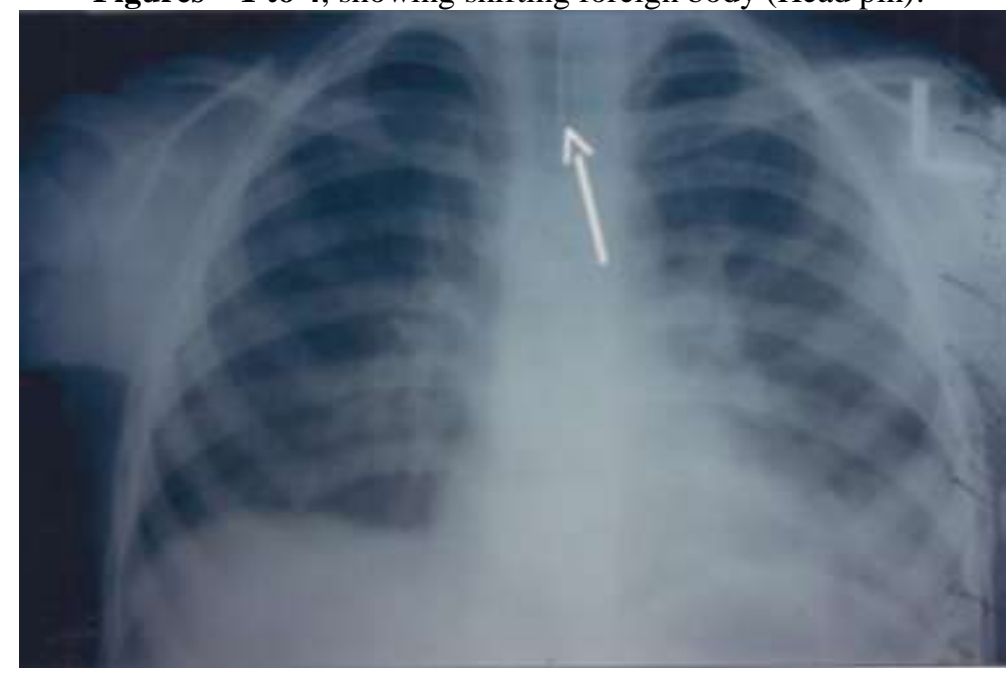

Fig - 1 First Radiological Evidence Of Head Pin In Trachea

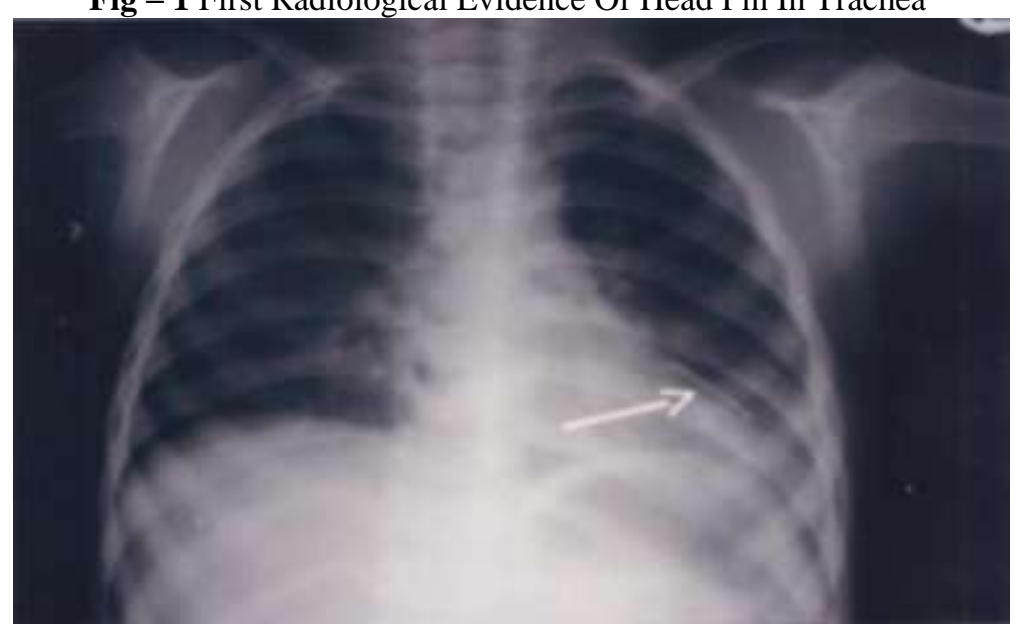

Fig - 2 Later Film Showing Head Pin In Left Segmental Bronchi in Lower Lobe

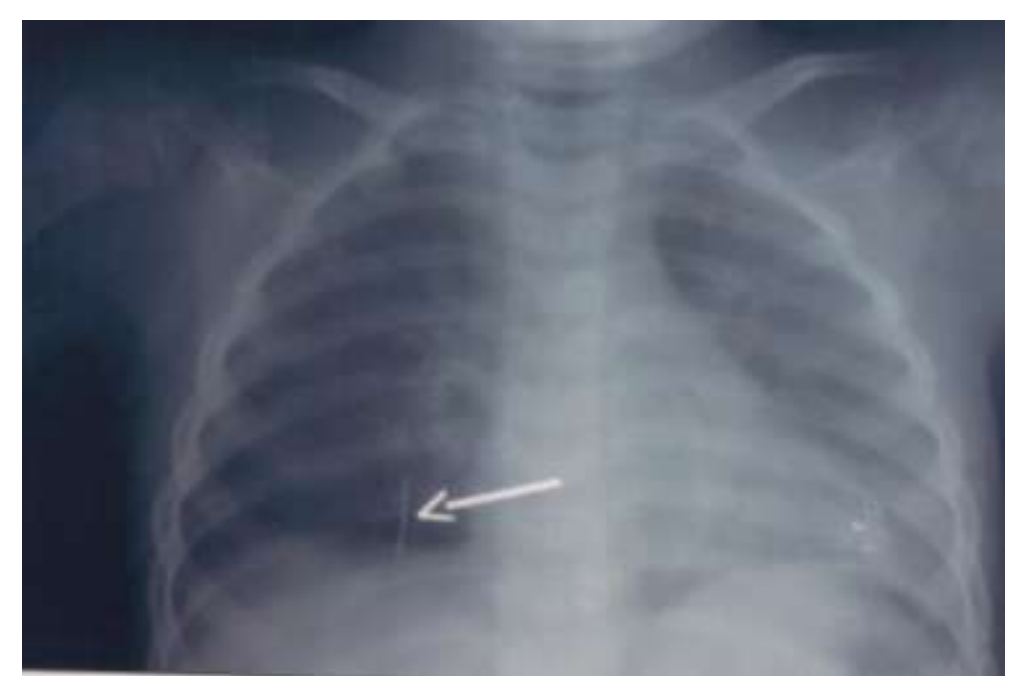

Fig - 3 pre - op x-ray chest pa view showing head pin in right segmental bronchus lower lobe. 


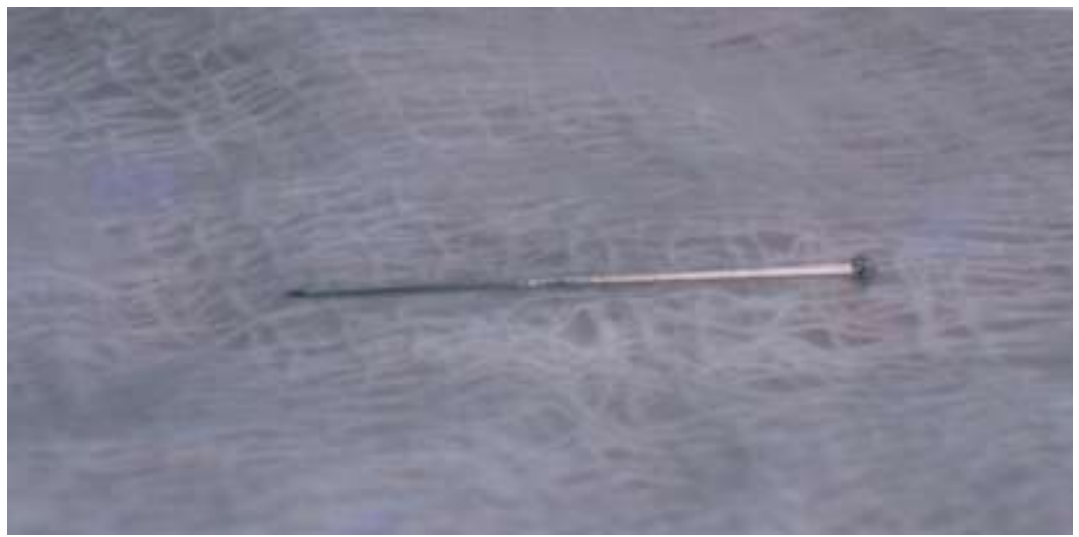

Fig - 4 Head pin removed after posterobasal segmentectomy of right lower lobe

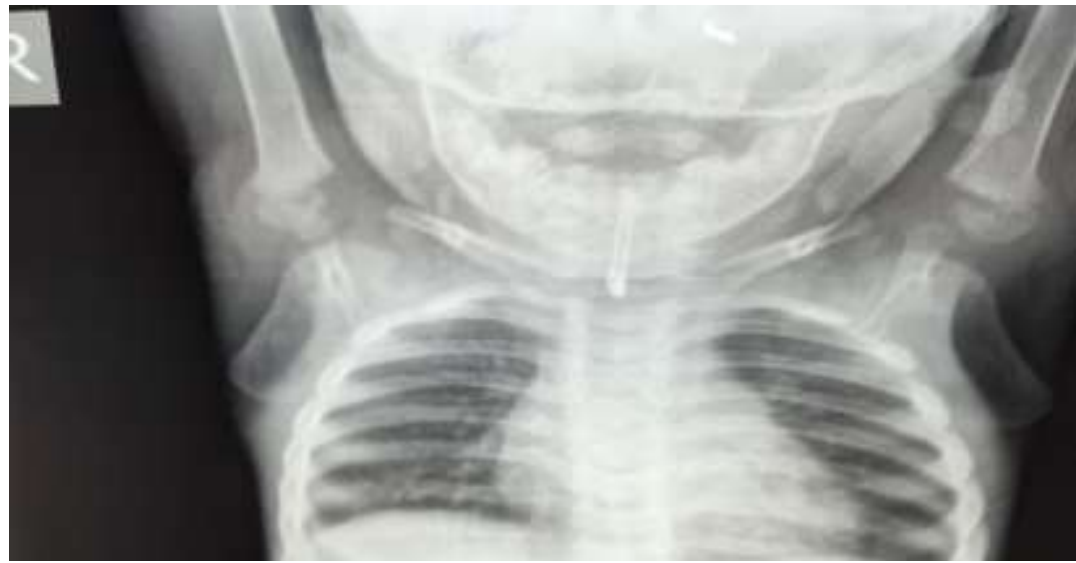

Fig $-\mathbf{5}$ Foreign body safety pin in trachea at the time of presentation

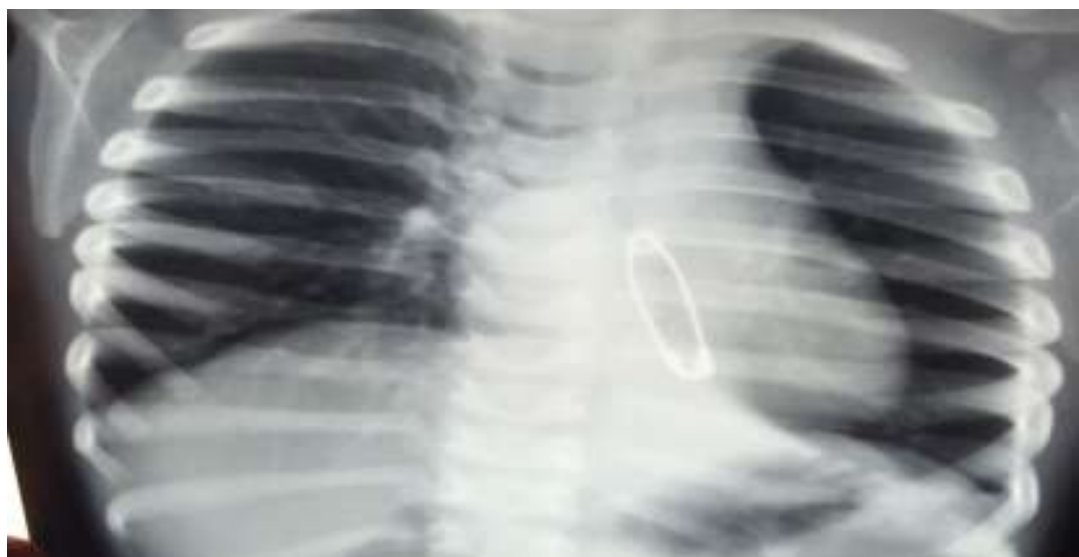

Fig - 6 Foreign body in left main bronchus after attempt of removal by bronchoscopy

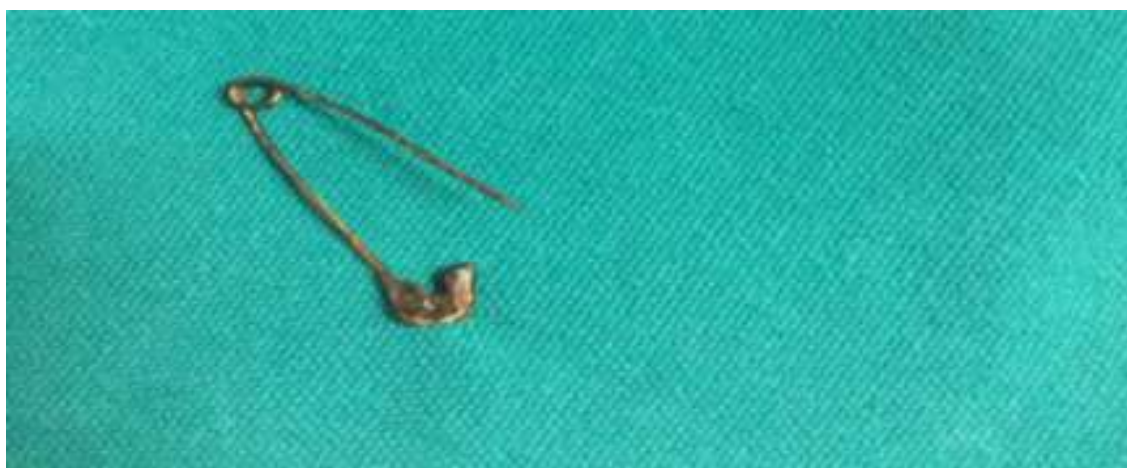

Fig - 7, Safety pin after bronchoscopic removal. 


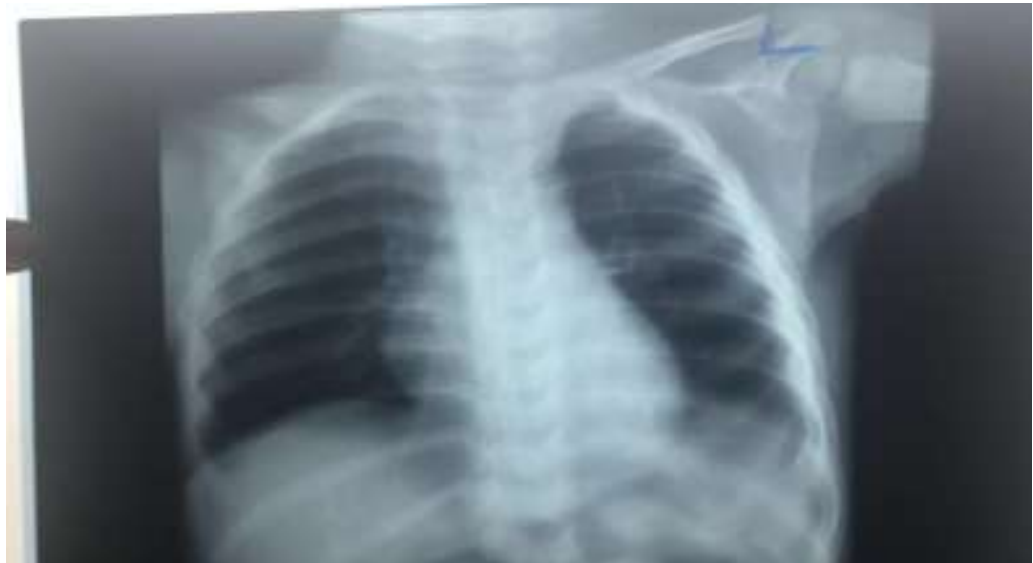

Fig - 8, Post- op Chest $\mathrm{X}$ - ray PA view after safety pin removal.

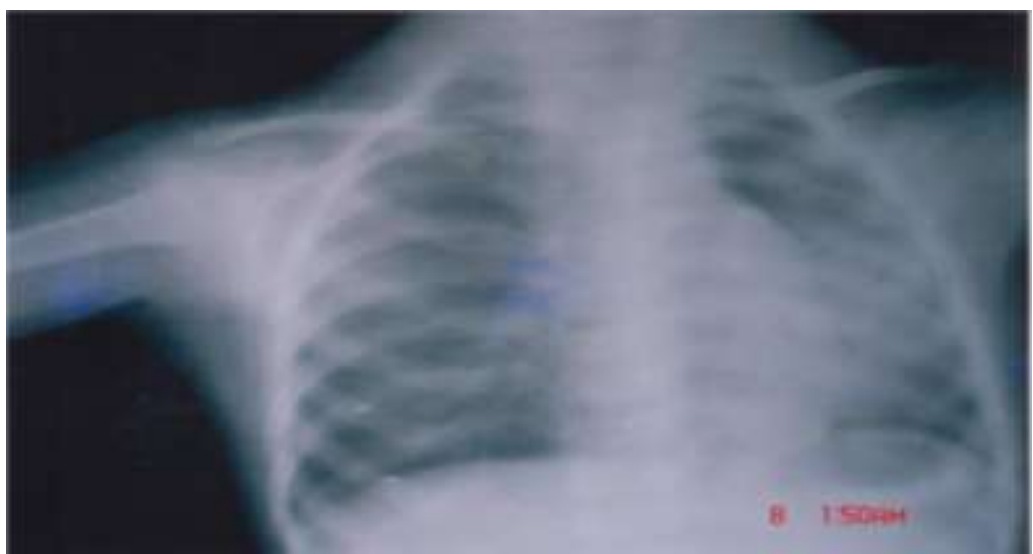

Fig.9, Left basal pneumonitis due to radiolucent FB

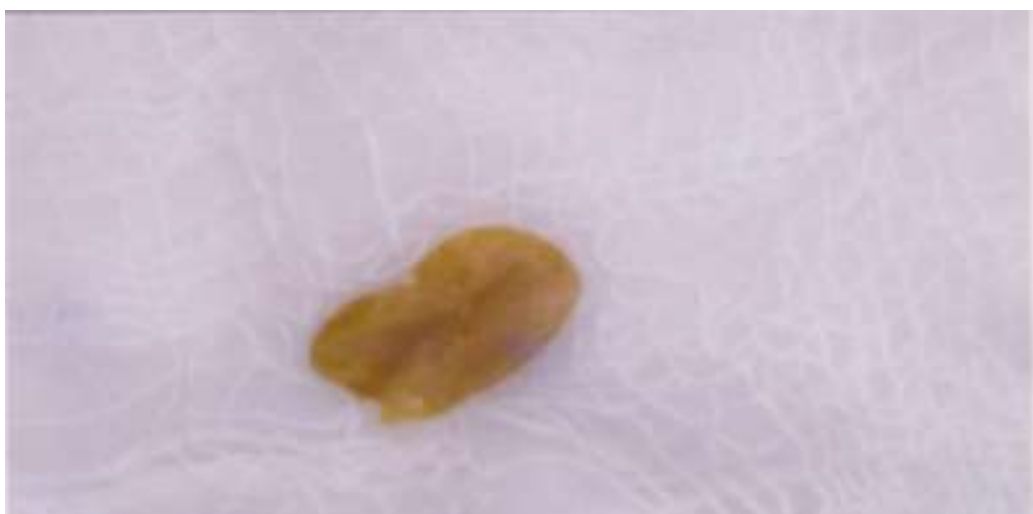

FIG.10, Peanut after removal by bronchoscopy.

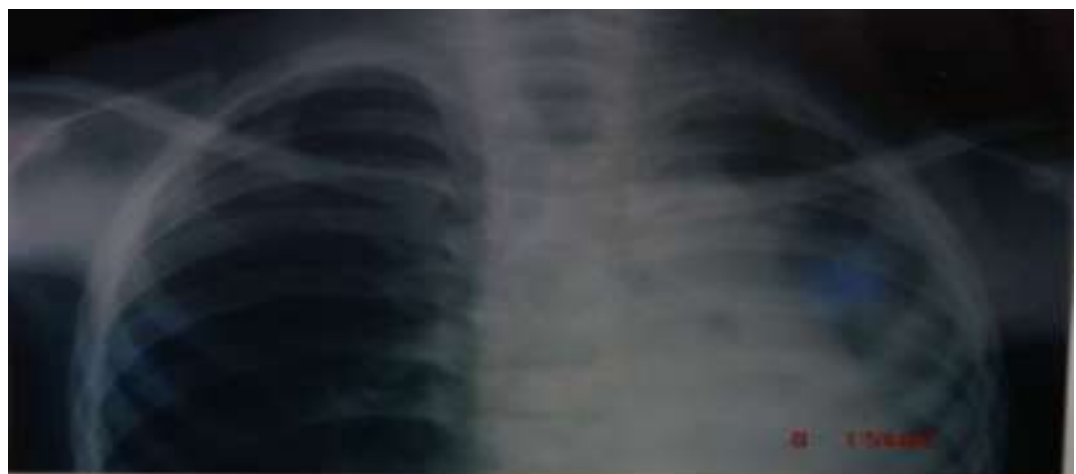

Fig. 11, Left basal pneumonitis due to radiolucent foreign body left main bronchus. 


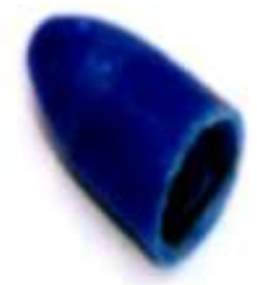

Fig.12, Pen cap after removal by bronchoscopy

Analysis of all patients revealed the symptoms suggestive of foreign body aspiration were: clear history of aspiration, coughing / choking, cyanosis and gagging. Late symptoms include fever, dyspnea and chest pain due to inflammatory reaction. Bronchoscopy was done under general anesthesia with appropriate rigid bronchoscope and foreign body removed with forceps. Among these patients two patients underwent tracheostomy, one tracheotomy and one thoracotomy with postero-basal segmentectomy of right lobe.

\section{Results}

Various types of foreign bodies were removed by rigid bronchoscopy under jet ventilation but in one case it was not possible to remove as it was sharp metallic foreign body presented unusually, hence we removed successfully by open method under general anesthesia that is postero-basal segmentectomy of right lobe through thoracotomy. Two cases required tracheostomy and one case tracheotomy. The types of FB's are charted in Table -3 . The various sites of lodgment of FB's are Glottis, Trachea, right and left main Bronchus and segmental Bronchus. The site of lodgment of FB's is charted in Table - 4

Table - 3. Types of FB's

\begin{tabular}{|c|c|c|}
\hline Type of FB & No. of cases & Percentage \\
\hline Peanuts & $\mathbf{8}$ & $\mathbf{1 6 \%}$ \\
\hline Wire & $\mathbf{1}$ & $\mathbf{2 \%}$ \\
\hline Ground nut & $\mathbf{3 0}$ & $\mathbf{6 0 \%}$ \\
\hline Safety pin & $\mathbf{2 \%}$ \\
\hline Carrot pieces & $\mathbf{6}$ & $\mathbf{1 2 \%}$ \\
\hline Pin head & 1 & $\mathbf{2 \%}$ \\
\hline coins & 1 & $\mathbf{2 \%}$ \\
\hline Betel nut & 1 & $\mathbf{2 \%}$ \\
\hline Tracheostomy tube & 1 & $\mathbf{2 \%}$ \\
\hline Total & $\mathbf{5 0}$ & $\mathbf{1 0 0 \%}$ \\
\hline
\end{tabular}

Table - 4. Sites of lodgment of FB's

\begin{tabular}{|c|c|c|}
\hline Location & No. of cases & Percentage \\
\hline Glottis & $\mathbf{1}$ & $\mathbf{2 \%}$ \\
\hline Trachea & $\mathbf{1}$ & $\mathbf{2 \%}$ \\
\hline Rt. Bronchus & $\mathbf{3 2}$ & $\mathbf{6 4 \%}$ \\
\hline Lt. Bronchus & $\mathbf{1 5}$ & $\mathbf{3 0 \%}$ \\
\hline Segmental bronchus & $\mathbf{1}$ & $\mathbf{2 \%}$ \\
\hline Total & $\mathbf{5 0}$ & $\mathbf{1 0 0 \%}$ \\
\hline
\end{tabular}




\section{Discussion}

This retrospective study of 50 cases of Foreign bodies in respiratory passages has been taken up over a period of three years from 2004 to 2007. Our study lays emphasis on the incidence of Foreign bodies, common age groups of presentation, sex distribution, nature of foreign bodies, site of lodgment, signs and symptoms' and radiological evidence, anesthesia and management are analyzed.

FB's are most commonly encountered in children in the age group of $3-4$ years. The location of the FB is more often in the right main Bronchus than the left side because of the wide angle of the Right Bronchus, lesser angle of deviation from tracheal axis, the situation of carina is to left of the mid line of trachea, the greater volume of air going in to right bronchus on inspiration. Most of the FB's are organic and majority of them are ground nuts, peanuts and carrot pieces. The gender distribution was males more common than females.

Many causes of aspiration of FB's are under consideration. Lack of molars for grinding, tendency to put small objects, inadequate chewing ability, swallowing while playing, lack of coordination between swallowing and respiration in young children. Jackson described the clinical pathophysiology of bronchial obstruction by FB. Initially obstructive emphysema occurs, later on consolidation and collapse of segment of the lung occurs due to complete obstruction. Certain vegetative FB's have fatty acids that can produce bronchopneumonia, flooding of the lungs causing severe respiratory distress and pneumonitis. Early removal of FB by Rigid Bronchoscopy with smaller sized bronchoscope under general anesthesia by jet ventilation can prevent hypoventilation. The techniques of anesthesia followed in ,our study are jet ventilation and spontaneous ventilation with ventilating broncos copy and local anesthesia in flexible bronscopy. Broncosopy was done under general anesthesia with appropriate rigid bronchoscope of proper size, which was determined by the following formula (in millimeters):-

\section{Size of the bronchoscope $(<6$ years of age $)=$ Age in years +3.5} 3

Size of the bronchoscope $(>6$ years of age $)=$ Age in years +4.5

Appropriate airway control was maintained throughout the procedure. After removal of foreign body, secretions were thoroughly sucked out and bronchial tree was carefully examined and post operatively steroids were used during or after removal of the foreign body if procedure is prolonged. In our study one patient required the intervention of CTVS surgeon and two cases required tracheostomy and one case required tracheotomy.

\section{Conclusion}

For removal of foreign bodies in respiratory tract most of the cases require rigid brochoscopy after their confirmation. A great number of foreign bodies were inhaled due to negligence and hurried eating. Chest $\mathrm{X}$ rays, careful history taking and clinical examination are very much helpful in confirming the diagnosis and in doubtful cases by flexible bronchoscopy especially in non radio opaque foreign bodies. Whenever necessary immediate tracheostomy was done as a preliminary measure for removal of the foreign bodies in trachea. The advancements made in endoscopic techniques during recent times coupled with safe anesthetic procedures like ventilating bronchoscopes have made removal of foreign bodies from tracheo - bronchial tree a relatively safe procedure followed by treatment with antibiotics and steroids whenever necessary.

\section{References}

[1]. Wolach B, Raz A, Weinberg J, Mikulski Y, Ben Ari J, Sadan N. Aspirated foreign bodies in the respiratory tract of children: eleven years of experience with 127 patients. Int J Pediatr Otorhinolaryngol 1994;30: 1-10.

[2]. Blaser S, Naveh Y, Friedman A. Foreign body in the air-way: a review of 200 cases. Am J Dis Child 1980;134:68-71.

[3]. Cohen SR, Lewis GB, Herbert WI, Geller KA. Foreign bodies in air-way-five year retrospective study with special reference to management. Ann Otol Rhinol Laryngol 1980;89:437-42.

[4]. Esclamado RM, Richardson MA. Laryngotracheal foreign bodies in children: a comparison with bronchial foreign bodies. Am J Dis Child 1987;141:259-62.

[5]. Mantel K, Butenandt I. Tracheobronchial foreign body aspiration in childhood: a report of 224 cases. Eur J Pediatr 1986;145:211-6.

[6]. Mofenson HC, Greensher J. Management of the choking child. Pediatr Clin North Am 1985;32:183-92.

[7]. Black RE, Johnson DG, Matlak ME. Bronchoscopic removal of aspirated foreign bodies in children. J Pediatr Surg 1994;29:682-4.

[8]. Pasaoglu I, Dogan R, Demircin M, Hatipoglu A, Bozer AY. Bronchoscopic removal of foreign bodies in children: retrospective analysis of 822 cases. Thorac Cardiovasc Surg 1991;39:95-8.

[9]. Hoeve U, Rombout J, Pot DJ. Foreign body aspiration in children. The diagnostic value of signs, symptoms and preoperative examination. Clin Otolaryngol 1993;18:55-7.

[10]. Thompson GP, Utz JP, McDougall JC. Pediatric tracheobronchial foreign bodies. A case report. Minn Med 1993;76:19-21. 
[11]. Soboczynski A, Skuratowicz A, Grzeqorowski M, ChwirotGlyda I. The problem of lower respiratory tract foreign bodies in children. Acta Otorhinolaryngol Belg 1993;47: 443-7.

[12]. Ballenger JJ. Foreign bodies of the tracheobronchial tree-bronchology. In: Diseases of the nose, throat, ear, head and neck, 13th ed. Philadelphia: Lea \& Febiger, 1985:1346- 52.

[13]. Mu LC, Sun DQ, He P. Radiological diagnosis of aspirated foreign bodies in children: review of 343 cases. J Laryngol Otol 1990; 104:778-82.

[14]. Black RE, Choi KJ, Syme WC, Johnson DL, Matlak ME. Bronchoscopic removal of aspirated foreign bodies in children. Am J Surg $1984 ; 148: 778-81$.

[15]. Kosloske AM. Bronchoscopic extraction of aspirated foreign bodies in children. Am J Dis Child 1982;136: 924-7. 